\title{
STUDIES ON CERTAIN GROWTH PARAMETERS OF DIFFERENT PROBIOTIC STRAINS
}

\author{
DUMITRA RĂDUCANU ${ }^{1}$, ANA-MARIA GEORGESCU ${ }^{1 *}$ \\ 1 "Vasile Alecsandri" University of Bacau, Calea Marasesti 157, Bacau, 600115, Romania
}

\begin{abstract}
The researchers found that probiotics contain microorganisms belonging to genus: Streptococcus, Lactobacillus, Bacillus, Aspergillus, Saccharomyces, Enterococcus, Pediococcus, enzymes (lactoperoxidase, gluconase, nonspecific enzymes) and rumen extracts. In this study, commercial probiotic bacteria known as "Linex" were used as samples. Cultural characteristics of these probiotic bacteria have been isolated and studied. It has been found that solid culture medium (nutritional gelose) favored the growth and development of bifidobacteria better than the liquid nutrient medium (nutrient broth). Thus, the number of bifidobacteria resulting from direct counting with Thoma chamber was of 7890 cells.
\end{abstract}

Keywords: probiotic bacteria, growth parameters

\section{INTRODUCTION}

It is well known that probiotics have their origins since 1903 when Metchnikoff in his studies observed the beneficial effects of yogurt consumption. Named like organism or substances that contribute to the microbial balance of the intestine by Lilly and Stillwell (1965) then by Parker in 1974, probiotics as bifidobacteria were first discovered and isolated from the feces of a newborn. Clinical studies releaved that are common constituents of the human intestinal microbiota $[1,2]$.

Probiotics are defined by FAO (2001) as "living microorganisms which, when administered in optimal doses, confer a benefit to the host." So, it is obvious that a real probiotic must accomplish certain conditions. First of all, at the time of probiotics ingestion, it is necessary for the microorganisms to be "alive". Secondly, it is necessary to ingest a dose high enough to be effective. The recommended dose is closely related to clinical documentation, which must be based on. Thirdly, probiotic microorganisms ingested must have a beneficial effect on the host. Most probiotic microorganisms are bacteria belonging to the genus Lactobacillus and Bifidobacterium. The uses of probiotics are multiple, new valences being discovered thanks to modern study technologies. Known as friendly bacteria, probiotics help to restore intestinal flora after antibiotic treatment, are recommended in intestinal transit disorders: indigestion, flatulence, constipation and diarrhea etc. The rhythm of our everyday life often imposes a chaotic lifestyle with much stress and an unbalanced diet, all of which directly affecting the health of digestive tract and, last but not least, of the body [3-5].

Probiotics are used in animal feed to prevent digestive disturbances, to increase the immunity and the zootechnical performance. Nowadays, numerous probiotic preparations are commercially available, these being based on microorganisms of genus: Streptococcus, Lactobacillus, Bacillus, Aspergillus, Saccharomyces, Enterococcus, Bifidobacterium, Pediococcus, on enzymes (lactoperoxidase, gluconase, nonspecific enzymes) and rumen extracts [6-8].

\footnotetext{
* Corresponding author, email: ana.georgescu@ub.ro

(C) 2017 Alma Mater Publishing House
} 
Published studies recommend characterization of probiotic strains in antibiotic resistance models, metabolic activities, and side effects during studies on human, incidents to consumers, probiotics generating excessive immune stimulation in susceptible persons and gene transfer (FAO/WHO 2002). Additionally, it is recommended to evaluate the lack of probiotic strain infectivity in immuno-compromised animals, to increase confidence in the probiotics safety. If the strain belonging to a known species would produce a toxin and would have a hemolytic potential, it should also be tested for these characteristics. In Europe, the strains belonging to the species Bifidobacterium animalis have obtained safety status in 2008 by the European Food Safety Authority (EPSA) [9$11]$.

Bifidobacterium animalis BB-12 is the best studied probiotic from the Bifidobacterium group. It is described in more than 300 scientific publications, of which more than 130 are clinical trial publications, being tested in clinical trials for over 25 years in preterm and elderly patients who received a dose of 100 colony-forming units (CFU) per day. Bifidobacterium animalis BB-12 has been shown in numerous clinical trials that it had beneficial effects on the health of gastrointestinal tract as well as on immune system health [12-14].

This paper presents several aspects of probiotic bacteria: their isolation from Linex market products, cultural observations, Gram staining, quantitative determinations and optimizing of nutrient medium in order to increase their biomass. Linex products first appeared in Slovenia in 1982 and are produced by Lek now part of Sandoz. The composition of Linex products includes three types of live lyophilized lactic acid bacteria, all of which being naturally found in normal intestinal microflora: Lactobacillus acidophilus, subsp. gasseri; Bifidobacterium infantis; Enterococcus faecium (Sandoz International GmbH, Holzkirchen Germany).

\section{EXPERIMENTAL}

\subsection{Materials and methods}

The working material used in this paper was the complex of probiotic bacteria from Linex group (Sandoz Pharma Services S.R.L, Bucuresti, Romania). Each Linex capsule contains at least $1.2 \times 10^{7} \mathrm{CFU}$ (colony-forming unit) of live lyophilized bacteria according to the manufacturer's prospectus [14].

In order to isolate, to grow and to develop these microorganisms, as well as to study their morphological, cultural and biochemical properties, a series of devices and culture media were used from Laboratory of Microbiology, Phytopatothology and Plant Physiology, Department of Biology, Ecology and Environmental Protection. The devices used were: microscope (Euromex, The Netherlands), autoclave (Raypa, 28 AES model), laminar flow hood (V 700 model), Thoma counting chamber, slides. The culture media [15] used were: the nutrient broth (g/L) (peptone $5.0 \mathrm{~g} / \mathrm{L} ;$ meat extract $3.0 \mathrm{~g} / \mathrm{L} ; \mathrm{NaCl} 5.0 \mathrm{~g} / \mathrm{L}$ ) and gelose nutritive $(\mathrm{g} / \mathrm{L})$ ([14]. peptone $5.0 \mathrm{~g} / \mathrm{L}$; meat extract $3.0 \mathrm{~g} / \mathrm{L} ; \mathrm{NaCl} 5.0 \mathrm{~g} / \mathrm{L}$, agar: $15.0 \mathrm{~g} / \mathrm{L}$ ). The culture media were autoclaved for 15 minutes at $121^{\circ} \mathrm{C}$. Final $\mathrm{pH}$ was $7.0 \pm 0.2$ at $25^{\circ} \mathrm{C}$.All reagents used were analytical pure and were purchased from Sigma Aldrich (Redox Lab S.R.L, Bucuresti, Romania).

The number of bacteria in Linex products developed on culture media is reported in volume units $(\mathrm{mL})$ and can be determined by several techniques $[15,16]$ presented below.

\section{a. Quantitative determination by direct counting after 48 hours from inoculation}

This technique is based on direct counting of cells under the microscope lens and involves the using of special blades - Thoma blade or Bürcker-Türck blade. The number of micro-organisms in one milliliter of sample is calculated according to the following formula:

$$
x=\frac{a \cdot 4 \cdot 10^{6}}{b}
$$

where: $\mathrm{x}$ is number of bacteria (cells) / $\mathrm{mL}$ of liquid; a -number of cells counted in squares taken into account (in principle five squares); $\mathrm{b}$ - number of squares in which counting was made (in principle $5 \cdot 16=80$ squares); $\mathrm{c}$ dilution of the examined liquid; $4 \cdot 10^{6}$ - coefficient for result expression at $1 \mathrm{~mL}$.

\section{b. Quantitative determination by $\mathrm{CFU}$ (colony-forming unit)}

By identification of CFU technique, the number of viable cells is indirectly determined by counting the colonies that appear on the surface or in the depth of a culture medium: 


$$
C F U=M \cdot c \cdot 10
$$

where: $\mathrm{M}$ is arithmetic mean of the colonies counted on three plates inoculated with the same dilution; $\mathrm{c}$ - inversion of the dilution from which the inoculation was made; 10 - reporting coefficient of results at $1 \mathrm{~mL}$.

\section{c. Qualitative determination by pure isolation of Linex probiotic bacteria}

In order to isolate in pure culture a bacterial species of the developed culture media, the dissemination technique of the studied product on solid media was used (Figure 1).

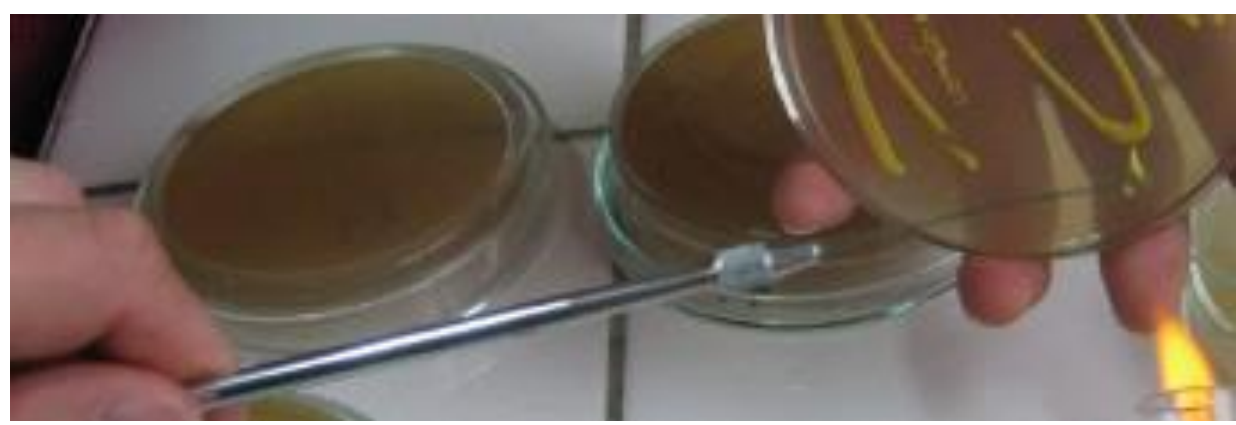

Fig. 1. Isolation of Linex probiotic bacteria in pure culture.

\section{d. Qualitative determination by Gram staining procedure of Linex probiotic bacteria}

Gram staining procedure is the widest used in microbiology and serves for diagnostic purposes, it being the first step in bacteria determination.

The required materials for this procedure are: $0.2 \%$ methyl violet; Pfeiffer fuchsin; alcohol-acetone 9:1 v/v; Lugol solution having the following composition: $200 \mathrm{~mL}$ distilled water, $2 \mathrm{~g}$ KI (potassium iodite), $2 \mathrm{~g}$ I (iodine).

\section{RESULTS AND DISCUSSION}

\section{a. Determination of the total number of cells by direct microscopic counting technique}

The experimental protocol consisted in the development of bifidobacteria in nutrient broth media followed by their counting. The major disadvantage of the method is the impossibility of differentiating the living cells from the autolyzed ones (Figure 2).
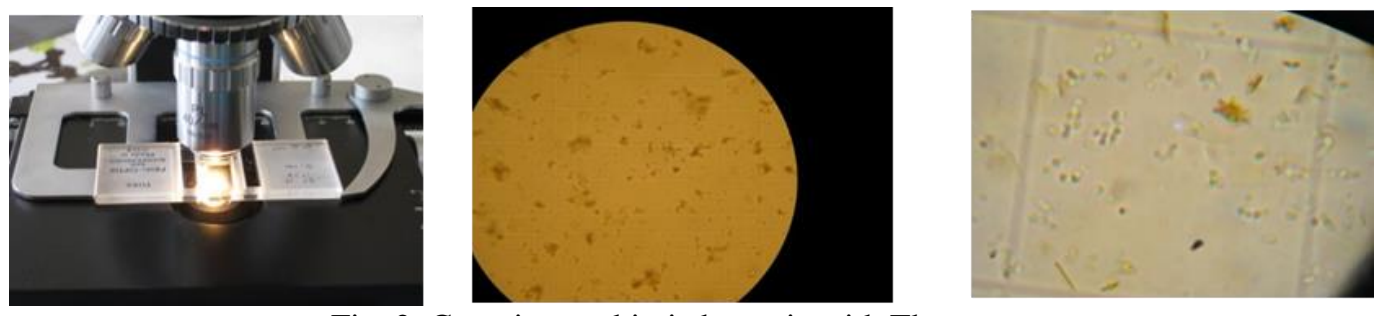

Fig. 2. Counting probiotic bacteria with Thoma camera.

Table 1 presents the results obtained on the number of probiotic bacteria on the two culture media, obtained by the microscope direct counting technique, by using Thoma camera.

Table 1 . Number of probiotic bacteria obtained by the direct counting technique.

\begin{tabular}{|c|c|c|c|}
\hline \multirow{2}{*}{ Sample } & \multirow{2}{*}{ Dilution } & \multicolumn{2}{|c|}{ No bacteria / $\mathrm{mL}$} \\
\cline { 3 - 4 } & & Nutrient broth culture medium & Gelose nutritive culture medium \\
\hline P1 & $10^{-1}$ & 5086 & 7890 \\
\hline P2 & $10^{-2}$ & 3408 & 5892 \\
\hline P3 & $10^{-3}$ & 2093 & 3110 \\
\hline
\end{tabular}


It can be seen that the number of probiotic bacteria (live and autolyzed cells) developed on gelose nutritive culture medium is significant to all three dilutions $\left(10^{-1}, 10^{-2}, 10^{-3}\right)$.

\section{b. Quantitative appreciation using CFU (colony-forming unit)}

According to the data obtained by the colony-forming units counting technique (CFU / mL), probiotic bacteria have developed on both media, this demonstrating that the nutritional requirements of these species are satisfied in both situations. This method of quantitative appreciation of only the viable number of probiotic bacteria (average of the three determinations) recorded the values presented in Table 2.

Table 2. Number of Linex probiotic bacteria by colony-forming units method identifying.

\begin{tabular}{|c|c|c|c|c|}
\hline \multirow{2}{*}{$\begin{array}{c}\text { Sample } \\
(100 \mu \mathrm{L})\end{array}$} & \multicolumn{3}{|c|}{ CFU /mL } & \multirow{2}{*}{ Average CFU /mL } \\
\cline { 2 - 4 } & $\mathrm{R} 1$ & $\mathrm{R} 2$ & $\mathrm{R} 3$ & 230000 \\
\hline Nutrient broth & 234000 & 242000 & 314000 & 238333 \\
\hline Gelose nutritive & 252000 & 267000 & 296000 & \\
\hline
\end{tabular}

It can be seen that the difference provided by the growing conditions is insignificant, $2 \%$ for the classical culture media used (nutrient broth / gelose nutritive) (Figure 3).
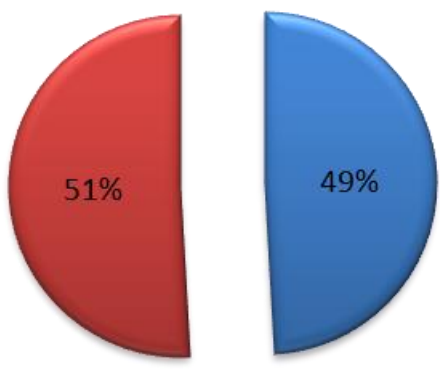

Nutrient broth

Gelose nutritive

Fig. 3. Average of Linex probiotic bacteria $(\mathrm{CFU} / \mathrm{mL})$ grown on culture media.

\section{c. Qualitative determination by pure isolation of Linex probiotic bacteria}

The colonies of probiotic bacteria isolated from Linex by proper microbiological technique are yellow cream, with small round colonies (Figure 1). From the aspect at the colonies looks like Lactobacillus (Figure 1) but is needed supplementary tests for exactly identify on species.

\section{d. Qualitative determination by Gram staining of Linex probiotic bacteria}

One of the objectives of this case study was Gram staining procedure and the observation on microscope of Linex probiotic bacteria. Gram staining procedure of Linex probiotic bacteria is presented in Figure 4.
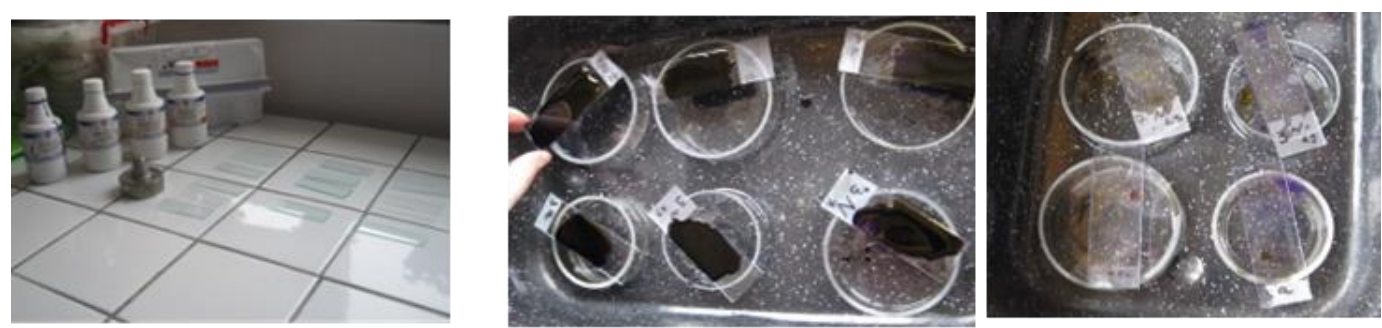

Fig. 4. Gram staining procedure of Linex probiotic bacteria.

According the Gram staining procedure and observation to microscope of Linex probiotic bacteria, it can be observed that studied bacteria were Gram positive (Figure 5). 

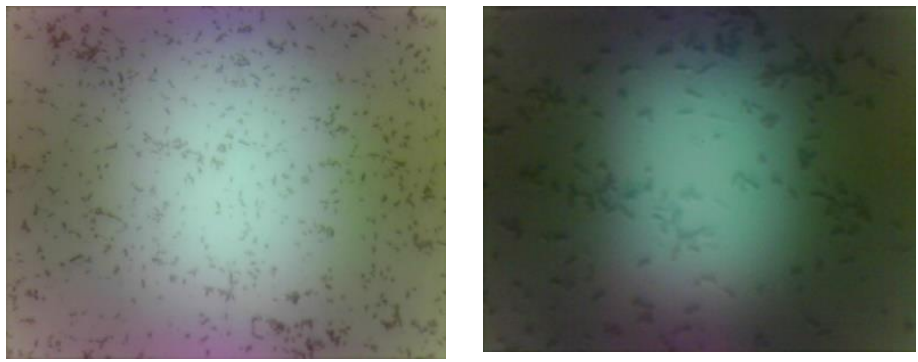

Fig. 5. Microscope images (40X) of Linex probiotics

\section{CONCLUSIONS}

Researches on "Linex" group of probiotics allowed their isolation in the laboratory and the observation of cultural aspects on culture medium (nutrient broth and gelose nutritive). Distinct colonies with different yellow cream nuances were observed on solid media. Both culture media used allowed the growth of Linex probiotic bacteria in a relatively close number, both media supplying the necessary nutrients. According to Gram staining procedure, it was found that Linex probiotic bacteria are Gram-positive bacteria.

This study on Linex probiotic bacteria will be continued with researches concerning the variations of culture medium components and the influence of certain parameters (temperature, $\mathrm{pH}$ ) on their growth and development.

\section{REFERENCES}

[1] Adlerberth, I., Ahrne, S., Johansson, M.L., Molin, G., Hanson, L.A., Wold, A.E., A mannose-specific adherence mechanism in Lactobacillus plantarum conferring binding to the human colonic cell line HT-29. Appllied Environmental Microbiology, vol. 62, no.7, 1996, p. 2244-2251.

[2] Reuter, G., The Lactobacillus and Bifidobacterium microflora of the human intestine: composition and succession, Cu Current Issues in Intestinal Microbiology, vol. 2, no. 2, 2001, p. 43-53.

[3] Brown, A.C., Valiere, A., Probiotic and medical nutrition terapy, nutrition in clinical care, an official publication of Tufts University, vol. 7, no. 2, 2004, p. 56-68.

[4] Boyle, R.J., Browne, R.M., Tang, M.L., Probiotic use in clinical practice: what are the risks?, American Journal of Clinical Nutrition (Review), 2006, vol. 83, no. 6, 2006, p. 1256-64.

[5] Hill, C., Guarner, F., Reid, G., Gibson, G., Merenstein, D.J., Pot, B., Morelli, L., Canani, R.B., Flint, H.J., Salminen, S., Calder, P.C., Sanders, M.E., The international scientific association for probiotics and prebiotics consensus statement on the scope and appropriate use of the term probiotic, Nature Reviews, Gastroenterology \& Hepatology, vol. 11, no. 8, 2014, p. 506-514.

[6] Włodzimierz, G., Anna, O., Anna, S., Probiotics, prebiotics and antioxidants as functional foods, Acta Biochimica Polonica, vol. 52, no. 3, 2005, p. 665-671.

[7] Larsen, S., Nielsen, P., Kaestel, E., Brockmann, M., Bennedsen, H.R., Christensen, D.C., Eskesen, B., Jacobsen, L., Michaelsen, K.L., Dose-response study of probiotic bacteria Bifidobacterium animalis subsp. lactis BB-12 and Lactobacillus paracasei subsp. paracasei CRL-341 in healthy young adults, European Journal of Clinical Nutrition, vol. 60, 2006 p. 1284-1293.

[8] Garrigues, C., Johansen, E., Pedersen, M.B., Complete genome sequence of Bifidobacterium animalis subsp. lactis BB-12, a widely consumed probiotic strain, Journal Bacteriology, vol. 192, no. 9, 2010, p. 2467-2478.

[9] Araya, M., Stanton, C., Lorenzo, M., Reid, G., Maya, P., Guidelines for the Evaluation of Probiotics in Food Probiotics in food: health and nutritional properties and guidelines for evaluation, Combined report of a joint FAO/WHO expert consultation on evaluation of health and nutritional properties of probiotics in food including powder milk with live lactic acid bacteria, Cordoba, Argentina, 1-4 October, 2001, p. 34.

[10] European Food Safety Authority (EFSA), nutrition and allergies (NDA); Scientific opinion on the substantiation of a health claim related to combination of bifidobacteria (Bifidobacterium bifidum, Bifidobacterium breve, Bifidobacterium infantis, Bifidobacterium longum) and decreasing potentially pathogenic intestinal microorganisms pursuant to Article 14 of Regulation (EC), EFSA Journal, no. 1924, 2006.

[11] Rizzardini, G., Eskesen, D., Calder, P.C., Capetti, A., Jespersen, L., Clerici, M., Evaluation of the immune benefits of two probiotic strains Bifidobacterium animalis ssp. lactis, BB-12 and Lactobacillus paracasei ssp. 
paracasei, L. casei 431 in an influenza vaccination model: a randomised, double-blind, placebo-controlled study, The British Journal of Nutrition, vol. 107, no. 6, 2012, p. 876-884.

[12] Matsumoto, M., Msakamoto, M., Benno, Y., Dynamics of fecal microbiota in hospitalized elderly fed probiotic LKM512 yogurt, Microbiology Immunology, vol. 53, no. 8, 2007, p. 421-432.

[13] Matsumoto, M., Benno, Y., Consumption of Bifidobacterium lactis LKM512 yogurt reduces gut mutagenicity by increasing gut polyamine contents in healthy adult subjects, Mutation Research, vol. 21, no. 22, 2004, p. 147153.

[14] Sanders, M.E., Guarner, F., Guerrant, R., Holt, P.R., Quigley, E.M., Sartor, R.B., Sherman, P.M., Mayer, E.A, An update on the use and investigation of probiotics in health and disease, US National Library of Medicine National Institutes of Healthvol, vol. 62, no. 5, 2013, p. 787-96.

[15] Dunca, S., Ailiesei, O., Nimitan, E., Stefan, M., Microbiologie aplicata, Casa Editorială Demiurg, Iasi, 2007. [16] Prisecaru, M., Stoica, I., Raducanu, D., Microbiologie generala, Editura Alma Mater, Bacau, 2015. 